International Journal of Agriculture, Environment and Bioresearch

Vol. 4, No. 03; 2019

ISSN: $2456-8643$

\title{
AGRO-MORPHOLOGICAL AND BIOCHEMICAL CHARACTERIZATION OF SQUASH (CUCURBITA MAXIMA DUCHESNE) ACCESSIONS CULTIVATED IN TUNISIA
}

\author{
HAMDI Khawla ${ }^{1}$, MOKRANI Khaoula ${ }^{1}$, RAZGALLAH Nessrine ${ }^{1}$ and TARCHOUN Neji ${ }^{1}$ \\ ${ }^{1}$ Laboratory of Vegetable crops/ High Agronomic Institute of Chott Mariem, Sousse, Tunisia
}

http://doi.org/10.35410/IJAEB.2019.0110

\begin{abstract}
Squash (Cucurbita maxima Duchense) is an important crop that is used as human food and animal feed. The main objective of the present study was to characterize morphological and biochemical properties of a Tunisian squash collection. Morphological analyses were performed using UPOV and IPGRI descriptors. While biochemical analysis included total soluble sugars, starches and carotenoid contents in the squash fruits. The morphological analysis showed that the squash accessions have significant differences in morphology. Clustering showed that accessions from the same region were grouped together. Data about their biochemical characteristics showed large variability. Also, high content of carotenoids (between 35.95 and $52.82 \mathrm{mg} / \mathrm{g}$ ) and total sugars $(1.89 \%)$ were observed in squash.
\end{abstract}

Keywords: Squash, morphological characterization, biochemical characterization, clustering, total sugars, starch, carotenoids

\section{INTRODUCTION}

Biochemistry has long been used to explain the relationships between plant taxa and to complement morphology, embryology and ecology (Stuessy 1990). In fact, plant products must be biochemically evaluated to understand their nutritional values (Sharma and Rao, 2013). In this context, several scientific works have evaluated the biochemical properties of squash. With a rich chemical composition, squash has become an important component in the human diet, showing not only antioxidant and anticancer effects, but also hypoglycemic and anti-inflammatory properties (Seroczyńska et al., 2014). In the same context, Tamer et al. (2010) demonstrated that squash is a healthy and functional vegetable because of its rich nutrients and bioactive compounds. Squash contains some phenolic components, flavonoids, vitamins (including $\beta$-carotene, vitamin A, vitamin B2, $\alpha$-tocopherol, vitamin $\mathrm{C}$ and vitamin $\mathrm{E}$ ), amino acids, carbohydrates and minerals (especially potassium). It has a low energy content (about $17 \mathrm{Kcal} / 100 \mathrm{~g}$ fresh squash) and a large amount of fiber. In addition, several studies have shown that cucurbits not only contain important biological compounds, but also have important nutritional effects, so it is necessary to biochemically analyze it (Omorayi and Dilworth, 2007). Indeed, carotenoids, methanol and certain types of sugars (polysaccharides) present in the pumpkin could reduce blood glucose and make insulin available in diabetic patients (Saha et al., 2012). Other studies by Fu et al. (2006) on C. 
maxima seeds and demonstrated their human health benefits due to their rich macro and microcomponent composition. It is a natural source rich in proteins, triterpenes, lignans, phytosterols, polyunsaturated fatty acids, antioxidant phenolic compounds, carotenoids, tocopherol and minerals. Carotenoids in squash are essential to plant life because it provides important photoprotective functions in chloroplasts during photosynthesis and serves as precursors to abscisic acid (Grotewold, 2006). Beyond their essential biological activities, carotenoids also accumulate in flower and fruit chromoplasts (Tanaka et al., 2008).

According to Santoni et al. (2000), biochemical descriptors are used to help the breeder identify his plant material. However, according to Rezig et al. (2012), the composition and physicochemical properties of squash seeds remain relatively unexplored, particularly for North African accessions. The determination of chemical properties would contribute significantly to the development of the potential of pumpkin seed oil in the cosmetic, pharmaceutical and food industries. Squash needs to be studied to understand its nutritional value, the potential for commercial cultivation in appropriate areas and changes in marketing (Sharma and Rao, 2013).

In this study, we have tried to study the agro-morphological proprieties and the biochemical profile of a Tunisian squash collection including a determination of total sugars and starch and an extraction of carotenoids.

\section{MATERIALS AND METHODS}

\subsection{Plant material used}

Thirteen local accessions of Cucurbita maxima (fruits) were purchased directly from the experimental station of the Higher Institute of Agronomy Chott-Mariem, Tunisia (between May and July 2017). Thirty-nine squash samples (Three from each morphotype) were selected visually to fulfil a level of ripeness, physical appearance and uniform color.

\subsection{Morphological characterization}

The Tunisian accessions of squash were grown in an open field in the experimental station of the Higher Agronomic Institute of Chott-Mariem (Tunisia). For the morphological characterization, the standards descriptors from the UPOV (2016) and the IPGRI (2007) were used. The phenotypic characterization was carried out on three fruits randomly harvested from each population. The following morphological-agronomic traits were measured: seeds length, width and ratio W/L, leaves length, width, shape and form, fruits weight, shape, peduncle length, skin thickness, flesh thickness, placenta length, placenta width and placenta ratio.

\subsection{Extraction and dosage of soluble sugars}

The total content of soluble sugars in pumpkin fruits was determined by the phenol-sulfuric acid method (Dubois, 1965). We put $0.3 \mathrm{~g}$ of fresh squash in test tubes. Then, we added $3 \mathrm{ml}$ of ethanol (80\%) and the mixture was left for 48 hours in the dark. At the same time, we mixed $20 \mathrm{ml}$ of distilled water in glass tubes with $1 \mathrm{ml}$ of phenol (5\%) and $5 \mathrm{ml}$ of concentrated sulfuric acid. We obtained a yellow-orange solution on the surface. we left the tubes to cool to room temperature and the tubes were shaken. The absorbance measurement was made at a wavelength of $640 \mathrm{~nm}, 1$ 
$\mathrm{ml}$ of each sample of fresh juice. A standard was prepared from a glucose solution with a concentration ranging from 0.25 to $4.5 \mathrm{~g} / \mathrm{l}$. Quantities are expressed in $\mathrm{mg} / \mathrm{g}$ MF. The total sugar content was determined using a calibration curve.

\subsection{Starches determination}

The enzymatic hydrolysis of starch in pumpkin fruits was made according to the protocol described by Millet (1959). This protocol consists of mixing $1 \mathrm{~g}$ of each sample (dry vegetable material) with $10 \mathrm{ml}$ of distilled water containing $100 \mathrm{ppm}$ of $\mathrm{CaCl}$. The first step (dextrinization) is to mix 1 $\mathrm{ml}$ from the solution with $200 \mu \mathrm{l}$ of $\alpha$-amylase. Then, the tubes were incubated in a water bath for 2 hours at $92 \mathrm{oC}$. When the temperature dropped to $60 \mathrm{oC}$, we added $40 \mu \mathrm{l}$ of AMG enzymes for the second step: saccharification (transformation of starch into glucose). The tubes were then completely hydrolyzed in the water bath for 12 hours at 60 to $65^{\circ} \mathrm{C}$. The reducing sugars were determined by spectrophotometry at $550 \mathrm{~nm}$ and the calibration was carried out with a glucose solution at $1 \mathrm{~g} / \mathrm{l}$.

\subsection{Extraction of carotenoids}

The $\beta$-carotene pigment was extracted according to the procedure recommended by Minguez et al. (1993). Ten grams of each sample of the flesh fruits were mixed with $1 \mathrm{~g}$ of sodium bicarbonate and then homogenized and extracted with acetone. The extracts were mixed and the acetone was evaporated at $35^{\circ} \mathrm{C}$ until $50 \mathrm{ml}$ of final volume was reached. The concentrate was transferred to an ampoule and mixed with $100 \mathrm{ml}$ of ethyl ether. $\mathrm{A} \mathrm{NaCl}$ solution (10\%) was added to separate the phases and transfer the pigments to ether. This solution was treated several times with a solution of $\mathrm{Na} 2 \mathrm{SO} 4$ anhydrous (2\%) to remove all the water. The ether layer was evaporated to dryness at $30^{\circ} \mathrm{C}$. The dry residue was then dissolved in a methanol $(1: 1, \mathrm{v} / \mathrm{v})$ ether mixture, filtered through a membrane $(0.45 \mathrm{~mm})$ and analyzed by HPLC. The preparation of the standard curves to evaluate the $\beta$-carotene pigment was carried out by pure $\beta$-carotene (Sigma Chemicol Co.) using the following concentrations: 3.12-6.25-12.5 and $25 \mathrm{Mg} / \mathrm{g}$ (Delia et al., 2004).

\section{RESULTS AND DISCUSSION}

\subsection{Morphological characterization}

Principal components of morphological characters

Characters with higher coefficients on the PC axes are considered more important. thus eigen vectors are shown in Table 1. PCA generalized 18 morphological characters to two principal components which explains the $41,25 \%$ of the total variability (Fig. 1). The first component accounted for $23,94 \%$ of the total variation, and was mainly defined by leaf length, peduncle length, leaf petiole length and seed length. The second component accounted for 17,31\% of the total variation and was correlated with seed ratio, petiole diameter, placenta width and fruit weight.

Table 1. Principal component analysis (PCA) of characters associated with the squash (C. maxima Duch) accessions. 
Vol. 4, No. 03; 2019

ISSN: $2456-8643$

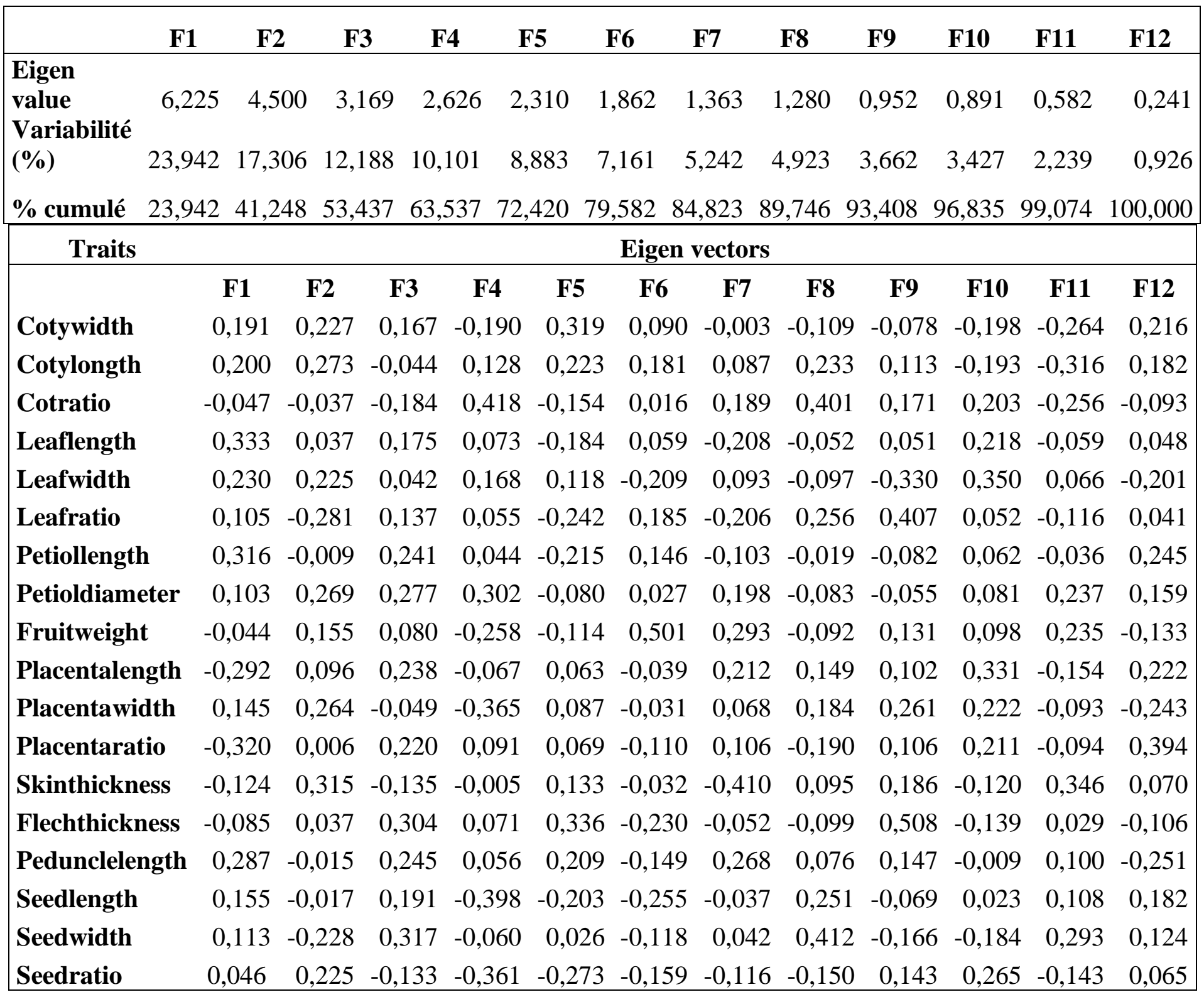

\section{Clustering of the Tunisian accessions}

The genetic similarities coefficients among all accessions ranged from 0.86 to 0.98 . Three clusters were evident with a similarity coefficient of 0.86 in the dendrogram (Fig. 2); two accessions (A6 and A8) in Cluster II were well separated from the 11 accessions classified in Cluster I and III. This analysis based on morphological characterization also revealed a sub-clustering structure that reflected geographical origins.

Cluster I is composed of five sub-clusters (similarity coefficient 0.92): sub-cluster I-I includes three accessions (A9 and A5) from Sehline, with small leaves, petioles and seeds and long 
cotyledons and accession 11 from Siliana, with large cotyledons and long leaves. All fruits in this cluster have big weight. In sub-cluster I-II, two accessions (A3 and A4) from Siliana are clustered together and have big seeds, small fruit weight and light skin. Accessions A13 from Sehline and A14 from Chott-Meriem possess strong growth vigor and are grouped together in sub-cluster IIII. Sub-cluster I-IV consists of two accessions (A10 and A12) from Sehline. Within this cluster, accessions have big cotyledons and petiole diameter, long seeds and small leaves. Sub-cluster I-V includes only one accession (A2) originating from Siliana which has long seeds, big leaves, big petioles and small fruits. Cluster II comprises two accessions (A6 and A8) which originate from Kalaat-Andalous, with a similarity coefficient of 0.93 . These accessions have small leaves, petioles and seeds, thicker flesh and round or ovate fruits. Cluster III contains only one accession (A7) which is native to Kalaat-Andalous and which has small seeds and low fruit weight.

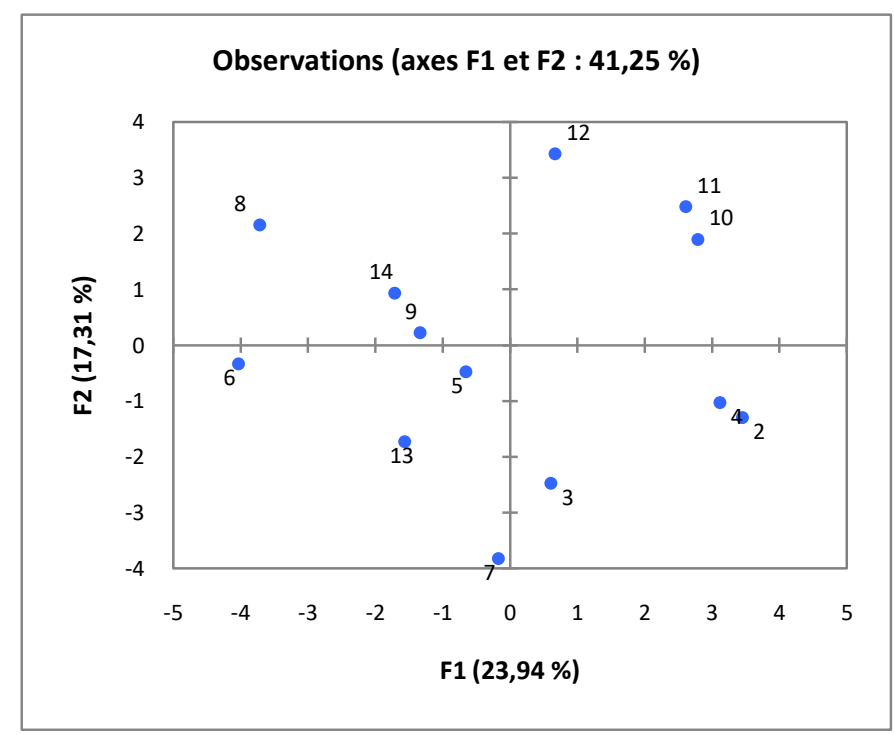

Figure 1. Diagram showing the relationships among the Tunisian accessions of C. maxima at the basis of the first 2 principal component axes using morphological characterization. 
Vol. 4, No. 03; 2019

ISSN: $2456-8643$

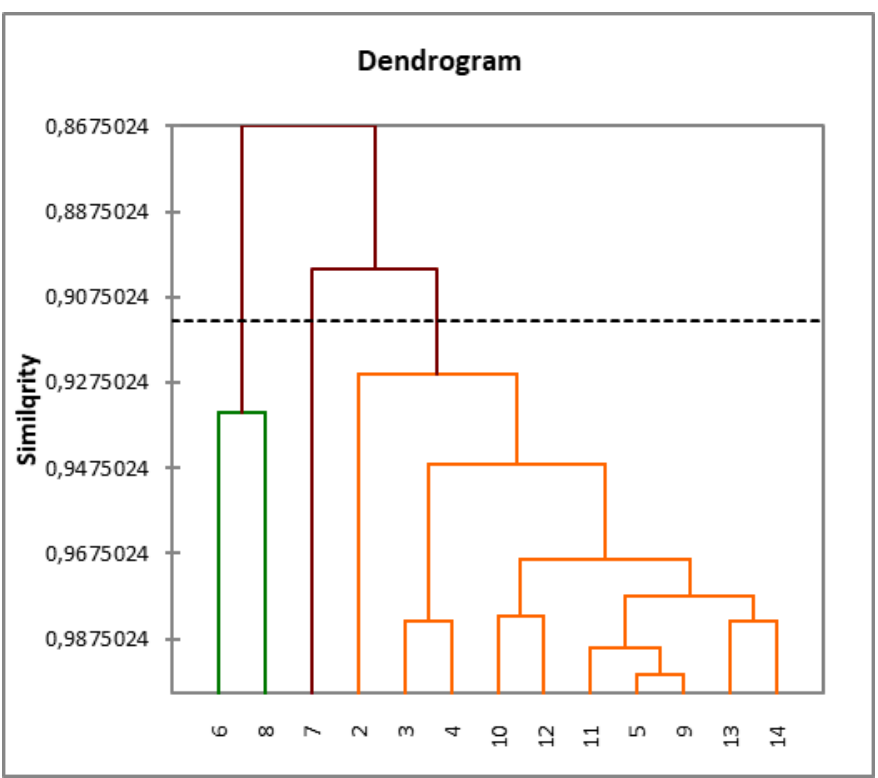

Figure 2. A dendrogram showing the relationships among the Tunisian accessions of C. maxima with morphological characters

The morphological characterization has revealed a great diversity in cotyledon, leaf, fruit and seed parameters within the Tunisian accessions. This diversity is comparable to that found by Chung et al. (1998) among 24 accessions of Cucurbita muschata in Kuria. Brown and Myers (2002) indicated that the most significant factors explaining the total variation are the fruit parameters. The values for seed shape and fruit weight were the largest coefficients of variation seen in the present study. In term of leaf characterization, Wehner (2008) considered leaf shape as a criterion genetically controlled in watermelon and it can serve as a discriminator between accessions. Hamdi et al (2017) found that 15 Tunisian accessions had oval leaves. The average value of fruit weight across accessions is $8.64 \mathrm{~kg}$ and average fruit weight of individual accessions varies from 4.55 to $13.24 \mathrm{~kg}$. Sharma and Rao (2013) showed a large variability in fruit weight. They obtained a weight mean for a collection of Indian squash accessions ranging between 1.5 and $2 \mathrm{~kg}$. We obtained a sub-cluster (I-I) that grouped four accessions with different geographic origins (North and Sahel of Tunisia). Many factors could lead to this confounding grouping situaion; Ferriol et al (2004a) suggested that the out-crossing nature of $C$. maxima suggested extremely rapid gene flow within regions. Liu et al. (2013) had found similar results within a germplasm collection including 10 Chinese seed genotypes of C. pepo and 38 Chinese and 28 Russian seed cultivars of C. maxima.

\section{Biochemical characterization}

ANOVA showed highly significant differences $(\alpha<0.01)$ between the different accessions for total sugar levels, starches and $\beta$-carotene (Table 2). Total sugar obtained from the pumpkin flesh varied between 0.83 and $2.45 \%$ with an average of $1.89 \%$. Kerkoubi rouge which originates from ChottMeriem has the lowest sugar levels, while Batati vert-grisatre which originates from KalaatAndalous contains the highest sugar levels. 
The rates obtained are close to those obtained by Jacobo-Valenzuela et al. (2011) in accessions of Cucurbita moschata D. that varied from 1.01 to $2.44 \%$. On the other hand, these rates are considered low compared to those found by Biesiada et al. (2009) who reported variability in sugar content for eight pumpkin morphotypes between $3.35 \%$ and $6 \%$.

The results obtained prove that the starch content in the flesh of pumpkin fruits varies from 3.54 to $12.87 \%$ with an average of $8.42 \%$. These results are considered low compared to previous work where researchers found starch levels in C. maxima fruits ranging from 3.3 to $41.4 \%$ (Graham Stevenson, 2011). Irving et al. (1997) demonstrated that squash is a starch-rich vegetable, which accumulates more starch during the fruit-ripening phase.

Provesi et al. (2011) reported that $\alpha$-carotene, $\beta$-carotene and lutein were the main carotenoids found in C. moschata and C. maxima. In this context, the $\beta$-carotene content in this fruit collection was between 35.95 and $52.82 \mathrm{mg} / \mathrm{g}$. Similarly, levels of carotenoids in an Indian pre-mature pumpkin collection were very low (0.6 to $7.47 \mathrm{mg} / 100 \mathrm{~g}$ ) compared to our results (Sharma et al., 2013) as it is well known that carotenoid biosynthesis increases during maturation or maturation of carotenogenic fruits and fruiting vegetables (Gross, 1987).

The biosynthesis and metabolism of carotenoids in vegetables can be significantly affected by differences in the growth environment, such as temperature, nutrient availability, soil, intensity of sunlight, stage of ripening and harvesting (Cazzonelli and Pogson, 2010).

Table 2: Biochemical composition of Cucurbita maxima flesh at maturity

\begin{tabular}{|lllll|}
\hline Variable & Min & Max & Mean & Ecart-type \\
\hline ST $(\%)$ & 0,835 & 2,457 & 1,894 & 0,437 \\
AM $(\%)$ & 3,541 & 12,871 & 8,421 & 2,292 \\
CR $(\mathbf{m g} / \mathbf{g})$ & 35,955 & 52,826 & 39,496 & 4,428 \\
\hline
\end{tabular}

\section{Principal Component Analysis of Biochemical Characteristics}

According to the principal component analysis, the $\beta$-carotene content is the parameter with the highest contribution in the construction of the first axis with a value of $0.18 \%$; it is positively correlated with the total sugar content and the starch rate of the squash fruits and negatively correlated with the carotenoid content. While axis 2 is composed mainly of the carotenoid content with a percentage of $0.19 \%$, this axis is negatively correlated with the levels of total sugars and starch (Table 3).

Table 3.: Contribution of variables in the construction of Axes 1 and 2 of the principal components analysis

\begin{tabular}{|lll|}
\hline & F1 & F2 \\
\hline ST & 0,066 & $-0,104$ \\
TS & 0,174 & $-0,151$ \\
\hline
\end{tabular}




\section{CR $\quad-0,029 \quad 0,193$}

Note: ST: starch rate, TS: total sugar content and CR: carotenoid content

It can be noted that there is a significant difference between squash types for all biochemical parameters $(\mathrm{P}<0.01)$. ACP divided the accessions into three main groups (Table 4): G1 contain Bejaoui-Vert-jaunatre and Batati-Blanc from Siliana, Kerkoubi-Rose foncé from Sehline and Batati-Vert grisatre from Kalaat-Andalous. This group has the highest average carotene content (40.157 $\mathrm{mg} \mathrm{g}^{-1}$ ). In squash, carotenoids are responsible for the development of yellow color in unripe fruit to mature orange color. Carotenoids play an important role in human nutrition and health because they are precursors of vitamin A, are lipophilic antioxidants and have anti-cancer properties (Singh and Goyal, 2008). These accessions had also the highest sugar levels with an average of $1.92 \%$. The sugar content of the fruit of the squash depends on the genotype as well as the hydrolysis of the starch during the storage of the fruits.

While the second cluster contains: Batati-Orangé Claire from Sehline, Batati-orangé from Siliana, Batati-Vert from Sehline and Kerkoubi-Rouge from Chott-Meriem. This group is characterized by the lowest levels of total sugars, starch and carotenoids $(1.73 \%, 7.006 \mathrm{mg} / \mathrm{g}$ and $37.019 \mathrm{mg} / \mathrm{g}$ respectively). This group contains the Batati-Vert accessions from Kalaat-Andalous and KerkoubiRose accessions from Chott-Meriem. The highest average starch content $(10.81 \mathrm{mg} / \mathrm{g}$ ) is found in group 3 containing only Kalaaoui accessions from Kalaat-Andalous).

Table 4: Biochemical parameters revealed by ACP

\begin{tabular}{|llll|}
\hline Cluster & ST & TS & CR \\
\hline $\mathbf{1}$ & 8,465 & 1,929 & 40,157 \\
$\mathbf{2}$ & 7,006 & 1,736 & 37,019 \\
$\mathbf{3}$ & 10,816 & 1,862 & 37,837 \\
\hline
\end{tabular}

The results of the present study show a great variability of biochemical characteristics between local Tunisian squash accessions. Sensoy et al. (2007) also recorded a large genetic variation in melon genotypes in Turkey. This study highlights the important morphological and biochemical characteristics in the squash flesh analyzed, indicating the need for further research to identify another biochemical characteristic of the Tunisian Cucurbita maxima accessions.

\section{REFERENCES}

1. Stuessy TF., 1990. Plant Taxonomy: The Systematic Evaluation of Comparative Data. Columbia University Press, New York 1990.

2. Sharma S. and Rao RTV., 2013. Nutritional quality characteristics of pumpkin fruit as revealed by its biochemical analysis. International Food Research Journal. 20(5): 2309-2316.

3. Tamer CE., İncedayi B., Parseker AS., Yonak S., Çopur ÖU. (2010). Evaluation of several Quality Criteria of Low Calorie Pumpkin Dessert. Not Bot Hort Agrobot Cluj 38:76-80.

4. Omorayi F.O. and Dilworth L., 2007. Anti-nutritional factors, zinc, iron and calcium in some cariggean tuber crops and effect of boiling or roasting. Nutr. Food Sci., 37: 8-15. 
5. Saha P., Bala A., Kar B., Naskar S., Mazumder UK., Haldar PK., Gupta M., 2012. Antidiabetic Activity of Cucurbita maxima Aerial Parts. Research Journal of Medicinal Plants. 5(5): 577-586.

6. Fu CL., Shi H. and Li QH., 2006. A Review on Pharmacological Activities and Utilization Technologies of Pumpkin. Plant Foods Hum. Nutr. 61: 73-80.

7. Grotewold E., 2006. The genetics and biochemistry of floral pigments. Annu Rev Plant Biol. 57: 761-780.

8. Tanaka Y., Sasaki N., Ohmiya A., 2008. Biosynthesis of plant pigments: anthocyanins, betalains and carotenoids. Plant J. 54: 733-749.

9. Santoni S., Faivre-Rampant P., Prado E., Prat D., 2000. Marqueurs moléculaires pour l'analyse des ressources génétiques et l'amélioration des plantes. Agricultures. 9 (4) : 311 327.

10. Reziga L., Chouaibia M., Msaadab K., Hamdia S., 2012. Chemical composition and profile characterisation of pumpkin (Cucurbita maxima) seed oil. Industrial Crops and Products. 37: 82- 87

11. Dubois M., Gilles K., Hamilton J.K., Rebers P.A., Smith F., 1965. Colorimetric method for determination of sugars and related substances. Anal. Chem., 28: 350-356.

12. Millet, C., 1959. Le projet hydro-électrique et industriel du Kouilou dans la République du Congo et les problèmes humaines posés par sa réalisation. Bulletin - Inter-African Labour Institute. 6 (5) : 9-35.

13. Minguez-Mosquera MI. and Hornero-Mendez D., 1993. Separation and quantification of the carotenoid pigments in red peppers (Capsicum annuum L.), paprika, and oleoresin by reversed-phase HPLC. J. Agric. Food Chem. 41 (10), pp 1616-1620.

14. Chung HD., Youn SJ., and Choi YJ., 1998. Ecological and morphological characteristics of the Korean native squash (Cucurbita moschata). (In Korean, with English abstract.) J. Korean Soc. Hort Sci. 39(4):377-384.

15. Brown RN., Myers RJ., 2002. A Genetic Map of Squash (Cucurbita sp.) with Randomly Amplified Polymorphic DNA Markers and Morphological Markers. Journal of the American Society for Horticultural Science. 127 (4): 568-575.

16. Wehner TC., 2008. Overview of the genes of watermelon, Cucurbitaceae, IX th EUCARPIA meeting, May 21.04.2008, Avignon, France, 79-89

17. Hamdi K., Ben-Amor J., Mokrani K., Mezghanni N., Tarchoun N., 2017. Assessment of the genetic diversity of some local squash (Cucurbita maxima Duchesne) populations revealed by agromorphological and chemical traits. Journal of New Sciences. 42(5): 23062317.

18. Ferriol, M., Picó, B., Córdova, P.F., Nuez, F., 2004a. Molecular diversity of a germplasm collection of squash (Cucurbita moschata) determined by SRAP and AFLP markers. Crop Sci. 44: 653-664.

19. Liu C., Ge Y., Wang D., Li X., Yang X., Cui C., Qu S., 2013. Morphological and molecular diversity in a germplasm collection of seed pumpkin. Scientia Horticulturae. 154: $8-16$.

20. Jacobo-Valenzuela N., Zazueta-Morales J., Gallegosinfante JA., Aguilar-Gutierrez F., Camacho-Hernández IL., Rocha-Guzman NE., Gonzalez-Laredo RF., 2011. 
Chemical and Physicochemical Characterization of Winter Squash (Cucurbita moschata D.). Not Bot Hort Agrobot Cluj. 39(1):34-40.

21. BIESIADA A., NAWIRSKA A., KUCHARSKA A., SOKÓŁ-ŁETOWSKA A., 2009. The effect of nitrogen fertilization methods on yield and chemical composition of pumpkin (Cucurbita maxima) fruits before and after storage. VEGETABLE CROPS RESEARCH BULLETIN 70. vol. 70, 203-211

22. Irving DE., Hurst PL., and Ragg JS., 1997. Changes in carbohydrates and carbohydrate metabolizing enzymes during the development, maturation, and ripening of buttercup squash (Cucurbita maxima D. 'Delica'). J. Amer. Soc. Hort. Sci. 122:310-314.

23. Provesi JG., Dias CO. and Amante ER., 2011. Changes in carotenoids during processing and storage of pumpkin puree. Food Chemistry. 128: 195-202.

24. Gross J., 1987. Pigments in Fruits. London: Academic Press.

25. Cazzonelli CI., Yin K., Pogson BJ., 2009. Potential implications for epigenetic regulation of carotenoid biosynthesis during root and shoot development. Plant Signalling \& Behaviour 4, 339-341. doi:10.4161/ psb.4.4.8193

26. Sensoy S., Buyukalaca S., Abak K., 2007. Evaluation of genetic diversity in Turkish melons (Cucumis melo L.) based on phenotypic characters and RAPD markers. Genetic Resources Crop Evolution. 54 (6): 1351-1365. 